\title{
Editorial
}

\section{Local Family Definitions Matter}

by

Siv Oltedal

Professor, PhD

University of Stavanger, Norway

E-mail: siv.oltedal@uis.no

Lennart Nygren

Professor, PhD

University of Umeå, Sweden

Email: lennart.nygren@socw.umu.se 
Child protection workers need to listen to local definitions of families. The importance of a family in social work varies depending on how much support and services the welfare from the state will- and can provide. In 1994, Ruth Lister developed the concept of defamilialized in order to capture the issue of to what degree an adult can maintain an acceptable standard of living independent of the family, either through the labour market or through welfare benefits. The concept was developed to address gender inequalities, and was further used and partially altered by other scholars (e.g. MacLaughlin and Glendinning) to make women's caring work more visible in society by focusing on the conditions under which people engage in caring relationships (see Kröger, 2011). The gender issue is of prevalent importance in child protection worldwide, which is shown in this issue. For instance, both patrilineal and matrilineal marriage systems illustrate the patriarchal impact on family practices in Malawi. And although the number of parents with shared custody after divorce is high in Iceland, the social workers' attitude towards the role of mothers and fathers in child protection cases is different. Mothers are expected to create support and security for the child, while social workers do not expect the same involvement from fathers in the upbringing of children.

In this issue, we get information about social work with families in Iceland, Norway, England and Malawi. In 2004, Linda Hantrais published a book called "Family policy matters", in which she presented different family policy regimes. Malawi can be regarded as familialized, in which the state delegates the responsibility for family wellbeing to the families themselves, who are under a legal obligation to look after their members. Consequently, childcare provision is relatively underdeveloped. As another case represented in this issue, England is defined as being partially defamilialized, i.e. that family policy lacks coherence, and is only partially co-ordinated and legitimized by the state. There is a high level of financial commitment to family policy. Iceland and Norway can be classified as defamilialized family policies typical of the northern European Nordic welfare states. State intervention in family life is legitimized, and there is a policy to minimize the reliance of individuals on their families. Labour market and gender equality policies have been important for Nordic states influenced by social democratic values, which appears to result in more individualistic support for family members, as well as a greater pressure in men to become active and participative fathers. 
In the article, "Narratives from parents in England and Norway: Power and emotions in child protection assessments", Vibeke Samsonsen and Elisabeth Willumsen write about how parents experience the duality of help and control differently in these two contexts. The risk dimension in England is rather explicit; hence, the parents know what to expect and the questions are the same for everyone. In Norway, professional judgement and reasoning are more in focus. The interviews reveal that Norwegian parents experienced helpful interventions, while in England parents had very limited expectations of getting help from the child protection system. Because of blurred and vague assessment processes, negative experiences in Norway are related to parents' feeling of powerlessness, and the article emphasizes that it is important to communicate about the topics of emotion and power to help improve the professional assessment in child protection cases.

The majority of the publications in this issue emanate from the international research network on "Social Work with Families" (SWF). We who are editing this issue have written an essay entitled, "Constructing a vignette for qualitative comparative family research." Here, we describe the international research project comprehending data from focus groups in 14 countries. By combining focus group interviews with social workers with a case vignette, our ambition was to get comparable and aspect-rich data about the conditions necessary to work with families with complex needs in different settings. Besides presenting the vignette, and hence making it possible to refer readers of future publications to it, the aim of this essay is to discuss some of the particular challenges and profits from using case vignettes in qualitative comparative research.

"The involvement of family in child protection cases in Iceland", written by Anni Haugen and Sigrun Yrja Klorudottir, is based on three focus group interviews as part of the SWF project. The findings highlighted how difficult child protection workers find it to define the family, as the workers tell that it is more complicated today than previously thought. The main element is that family are those individuals closest to the child and connected to them through emotional ties. When working with complicated cases, the definition of a family is restricted mostly to parents and grandparents. Findings also show that attitudes toward fathers differ from attitudes toward mothers. The mother is expected to support and create security for the child, whereas the father is judged mostly on his behaviour 
and is not automatically regarded as providing support or actively taking responsibility for his child.

The article, "Social Work in child welfare in Malawi: Social Workers Consideration when Placing a Child Outside the Home", written by Memory J. Tembo and Siv Oltedal, is based on two focus group interviews with practicing social workers. They found the absence of the extended family in the above-mentioned SWF vignette to be problematic. The discussion highlighted that social workers rely on the family as a resource to the child in different ways, and in this case the family is seen as the problem solver. This can result in stigmatization for a child to not stay in contact with his or her family. A focus group participant tells that no matter the behaviour of the man, he is still respected and regarded as the head of the family, and thus needs to be informed about decisions for this child. Over the years most African states, including Malawi, have gradually assumed a greater role as the principal source of social protection for children. Still, the family, the community and the church are important welfare providers. Social workers' professional discretion when placing a child outside the home is challenged by patriarchal systems, cultural and economic aspects that can be of hindrance to such a decision. Malawian social workers emphasized the importance of helping children within the immediate and extended family, thereby ensuring that the child grows up in a familiar environment that helps the child to feel the vibe of the family.

As demonstrated in this issue of the Journal of Comparative Social Work, it is important to get descriptions and analysis from different countries of child protection practices and how families are involved. By comparing observations and reflections about practices and professional reasoning from users and social workers within different family policies, we will be able to highlight that local definitions of the notion of family matter. An awareness of this may help reduce the risk that we interpret a description of a new case too narrowly into what we take for granted, following unquestioned norms in the systems and previous institutional practices. Changing practices needs to be accompanied by an increased consciousness about what we are actually doing, thus linking this to phenomenology and interactionism by the Thomas theorem: How we define a situation has consequences upon how we act in the situation. 
Journal of Comparative Social Work 2015/1

\section{Reference}

Kröger, T. (2011)."Defamilisation, dedomestication and care policy: Comparing childcare service provisions of welfare states", International Journal of Sociology and Social Policy, 31(7), 424 - 440. 